\title{
Cost-Benefit Analysis of Vishnugad-Pipalkoti Hydro-Electricity Project
}

\author{
Bharat Jhunjhunwala \\ Formerly Assistant Professor, Indian Institute of Management, Bengaluru, India
}

Email address:

bharatjj@gmail.com

\section{To cite this article:}

Bharat Jhunjhunwala. Cost-Benefit Analysis of Vishnugad-Pipalkoti Hydro-Electricity Project. International Journal of Economy, Energy and Environment. Vol. 6, No. 2, 2021, pp. 35-45. doi: 10.11648/j.ijeee.20210602.13

Received: March 24, 2021; Accepted: April 22, 2021; Published: April 30, 2021

\begin{abstract}
Hydroelectricity is often considered to be "clean" in view of less carbon emissions especially in comparison to thermal power. However, hydropower is intrusive in the natural environment and has many environmental costs that may outweigh the benefits from reduced carbon emissions. Hydroelectricity projects (HEPs) in India are required to submit a CostBenefit Analysis (CBA) statement in the approval processes. However, the monetary value of the environmental costs is not required to be calculated and not considered in the approval process. Thus, the projects are approved even if the costs are greater than the benefits. The projects are required to submit an "Environment Management Plan" (EMP) to mitigate the adverse environmental impacts. However, the proposals made in the EMP are inadequate to mitigate the impacts and are more cosmetic than real. The calculation of monetary value of environmental impacts is resource intensive. This paper suggests that proxy values can be used to arrive at an estimate. Ignoring the environmental costs because of absence of robust estimates is tantamount to assuming that the environmental costs are zero which is not plausible. Taking the Vishnugad-Pipalkoti HEP as an example, it is shown that the project overestimates the benefits and underestimates the costs. The Cost-Benefit Ratio (CBR) is less than 1 irrespective of whether the environmental benefits and costs are included or excluded. The paper argues that hydropower is not as green as often said to be.
\end{abstract}

Keywords: Hydroelectricity, Cost-Benefit Analysis, Environmental Costs, Environment Management Plan, Proxy Values, Carbon Emissions

\section{Introduction}

\subsection{Background}

Hydroelectricity is often considered to be "clean" in view of less carbon emissions especially in comparison to thermal power. However, hydropower is intrusive in the natural environment and has many environmental costs that are more frequently than not ignored.

The hydroelectricity projects (HEPs) in India are required to submit a Cost-Benefit Analysis (CBA) statement in two statutory approval processes. Public Sector Undertakings are required to submit a $\mathrm{CBA}$ to the Public Investment Board (PIB) which vets it and then submits it to the Cabinet Committee on Economic Affairs (CCEA) for approval of the public investment. This CBA only calculates the private costs and benefits and entirely ignores the environment costs and benefits. The second requirement to submit a CBA is under the Forest Conservation Act. This CBA is required to be submitted when forest land is diverted for non-forest purposes such as in the HEPs. The environmental costs in this CBA are restricted to the direct costs of forests known as Net Present Value of the ecological services of the forests. Non-forest environmental impacts such as on biodiversity are not accounted in this CBA.

The HEPs are required to submit an Environment Impact Assessment (EIA) statement to the Ministry of Environment, Forest and Climate Change (MOEFCC). There is no requirement to submit a CBA along with this statement. The HEPs are also required to submit an Environment Management Plan (EMP) which sets out the measures the HEP will take to protect the environment. These measures are theoretically proposed to mitigate the environmental impacts assessed in the EIA. Certain financial outlays are proposed in the EMPs. It is then assumed that these outlays will fully mitigate the environmental impacts although no monetary 
value is placed on the environmental impacts. It is possible that a negative environmental impact of Rs 100 may require an expenditure of Rs 10 or Rs 1,000. Such an assessment is not done. As a result, the policy makers have no inkling about the monetary value of the environmental impacts and whether the expenditures proposed in EMP fully mitigate or compensate for the same. Finally, there is no requirement for undertaking a comprehensive CBA that would include both the financial and environmental costs and benefits.

The calculation of environmental costs is resource intensive. I had made a presentation before the Expert Appraisal Committee of MOEFCC which recommends the issuance of an Environment Clearance. The Committee appreciated the need for undertaking a comprehensive CBA of a project. However, it said that this could not be required because it required considerable deployment of resources. This paper suggests that proxy values can be used to arrive at an estimate. Ignoring the environmental costs because of absence of robust estimates is tantamount to assuming that the environmental costs are zero which is not plausible. This paper shows that it is possible to undertake a CBA with nominal resources by using proxy values. We have undertaken a CBA of the Vishnugad Pipalkoti HEP to illustrate the possibility of undertaking a CBA with proxy values.

\subsection{VPHEP}

The Vishnugad-Pipalkoti Hydro Electricity Project (VPHEP) was given approval by the Cabinet Committee of Economic Affairs of the Government of India (GOI) on 21.08.2008 to be completed at an expenditure of Rs 24.91 Billion. The Project as approved was to be completed in 54 months in 2013. However, the Forest Clearance for the diversion of forest land for non-forest purposes was obtained only in December 2013 and the project was rescheduled to be completed, as per the promoter THDCIL Limited, in July 2018. However, the Project could not be completed on this revised date and, at the time of writing, it was scheduled to be completed in December 2022 at a revised cost of Rs 43.97 Billion.

\section{Benefits}

\subsection{Consumption of Electricity}

\subsubsection{Peaking Power}

THDCIL has averred that "hydropower is used for peaking purpose... Therefore, abandoning of VPHEP... is not in the interest of the nation." [1]

The question of Peaking Power was raised in Public Investment Board (PIB) meeting in 2007 when investment in VPHEP was approved by Government of India (GOI). THDCIL had replied:

Regarding the project being undertaken as a run of the river project, he clarified that around $30 \mathrm{~km}$ long stretch of National Highway from Tehri to Badrinath was getting submerged under the reservoir scheme; to avoid which, the location of the project was shifted by $2 \mathrm{~km}$ upstream and the project was made a run of the river project. [2]

Thus, the project is not a peaking project and benefits cannot be claimed on this ground. There will be no contribution of the project to grid stability.

\subsubsection{Consumption of Electricity}

The electricity produced by VPHEP will be supplied to consumers who will benefit from its use. The average price of electricity on India Energy Exchange was Rs 3.38 per unit in 2011-14 and Rs 3.07 per unit in 2015 -19:

Table 1. Price of Electricity on India Energy Exchange (IEX).

\begin{tabular}{llll}
\hline YEAR & AVERAGE & PEAKING PRICE & NON-PEAKING PRICE \\
\hline 2011 & 3.56 & 4.19 & 3.35 \\
2012 & 3.55 & 3.92 & 3.4 \\
2013 & 2.82 & 3.14 & 2.72 \\
2014 & 3.59 & 4.01 & 3.44 \\
2015 & 2.81 & 3.12 & 2.71 \\
2016 & 2.40 & 2.67 & 2.30 \\
2017 & 3.01 & 3.60 & 2.82 \\
2018 & 3.93 & 4.80 & 3.64 \\
2019 & 3.20 & 3.92 & 2.96 \\
Average (2011-14) & 3.38 & 3.81 & 3.22 \\
Average (2015-19) & 3.07 & 3.62 & 2.88 \\
\hline
\end{tabular}

The price has declined by Rs 0.31 per unit in the last five years. We may assume it will continue to decline at the same rate to Rs 2.76 in 2023-24 when VPHEP is scheduled to be completed. However, we ignore this further decline because of the uncertainty involved, and assume that electricity will be available on IEX at Rs 3.07 per unit in 2023-24.

The Energy Research Institute has assessed that the "Willingness to Pay" (WTP) is Rs 3.74 per unit: [3]

Table 2. WTP of Electricity.

\begin{tabular}{lllll}
\hline & & Grid (actual) & Grid (improved quality) \\
\hline 1 & Per day connected load & 300 & 300 & \\
2 & Monthly consumption & 45 & 45 & $\mathrm{~W}$ \\
3 & Monthly expenditure & 168 & 290 \\
4 & Average tariff (3/2) & 3.74 & 6.44 \\
\hline
\end{tabular}


We take WTP for the present quality of supply at Rs 3.74 per unit as being applicable for the electricity that would be produced by VPHEP. We do not take the higher WTP of 6.44 per unit for improved quality of supply because the quality issue is solely of distribution and not relevant for the Cost-
Benefit Analysis of the project.

The cost of electricity or the tariff likely to be approved by Central Electricity Regulatory Commission (CERC) is calculated as follows:

Table 3. Likely Tariff.

\begin{tabular}{lllll}
\hline SI & Item & Unit & Value & Basis \\
\hline 1 & Levelized Cost & Rs/unit & 3.92 & $\begin{array}{l}\text { CEA calculations supplied under RTI Act. } \\
\text { Debt-Equity Ratio is 70:30 as per VPHEP Progress Report of June 2019. Project cost is Rs 43.97 Billion. }\end{array}$ \\
2 & $\begin{array}{l}\text { Profit load on } \\
\text { levelized cost }\end{array}$ & Rs/unit & 1.12 & $\begin{array}{l}\text { Equity component is Rs 13.19 Billion. CERC may add 14\% return of equity=Rs 1.85 Billion/year. This will be } \\
\text { loaded on design energy of 1.657 Billion Units @ Rs 1.12 per unit. }\end{array}$ \\
3 & Likely Tariff & Rs/unit & 5.04 & \\
\hline
\end{tabular}

The three critical values for assessment of benefits from the generation of electricity are as follows:

Average Price of Electricity on IEX: Rs 3.07/unit

WTP for Electricity: Rs 3.74/unit

Likely tariff for VPHEP: Rs 5.04/unit

The benefit to the consumer is the difference between WTP and cost of supply. In the present case WTP is Rs 3.74 per unit while cost of supply from VPHEP is Rs 5.04 per unit Thus, the consumer will suffer a loss of Rs 1.97/unit.

The design energy is Rs 1.657 Billion units/year. Of this, 12 percent or 0.199 Billion units will be provided to state Government of Uttarakhand (GOUK) as royalty; and one percent or 0.016 Billion units will be provided free for local area development. Remaining 1.442 Billion units will be supplied to the buyers. The cost to the consumer from VPHEP will be Rs 2.841 Billion/year (1.442 Billion units $\mathrm{x}$ Rs 1.97 per unit).

\subsection{Royalty and Local Area Development}

As said above, 12 percent or 0.199 Billion units will be provided to GOUK as royalty; and one percent or 0.016 Billion units will be provided free for local area development. These benefits are valued below.

Benefit to GOUK from Royalty 0.199 Billion units@ Rs 3.07 being the price at which the same electricity is available on IEX=Rs 0.611 Billion/year.

Benefit to local people on 0.016 Billion units @ Rs 3.07 being the price at which the same electricity is available on IEX=Rs 0.049 Billion/year.

\subsection{Profits of THDCIL}

CERC is likely to provide for a return of $14 \%$ on the equity component of Rs 13.19 Billion or Rs 1.847 Billion/year in fixation of the tariff.

\subsection{Employment}

THDCIL has stated in the Cost-Benefit statement filed with MOEFCC under the Forest Conservation Act that employment of 2600 person for 5 years will take place. The monetary value of benefits@ Rs 400 per man day on 300 days per year is Rs 1.56 Billion. Annualized benefit @ 10\% will be Rs 0.156 Billion/year. Actually, the benefit would be the difference between the wages paid and the opportunity cost of labour. However, we take the wages to be the benefit to make a best-case scenario in favour of continuation of the project.

\subsection{Environmental Benefits: Carbon Emissions Saved}

The major argument in favour of hydroelectricity is the savings of carbon emissions. The carbon emissions from thermal power in India are estimated at 0.91 to $0.95 \mathrm{~kg} / \mathrm{kWh}$ or, say. $0.93 \mathrm{~kg} / \mathrm{kWh}$. [4] The value of carbon credit is estimated at USD 20.11 per tonne or Rs 1508 per tonne at an exchange rate of Rs 75 per USD.[5] The benefits are calculated as follows.

$$
\text { Design Energy=1.657 BU/year }
$$

Carbon emissions saved $=1.657 \mathrm{BU} /$ year $\mathrm{x} 0.93$

$\mathrm{kg} /$ Unit=1.541 Million Tonne/year

Value of Carbon Saving=1.541 x 1508=Rs 2.324 Billion/year.

\section{Costs}

\subsection{Investment by THDCIL}

According to the Progress Report of the Project available on THDCIL website, THDCIL has submitted a revised cost estimate of Rs 43.97 Billion in February 2019 to Ministry of Power. The debt component is serviced by Interest During Construction (IDC) and included in the cost. The equity component of the project Rs 13.19 Billion is the investment made by THDCIL. The annualized cost of investment @10\% may be taken as Rs 1.319 Billion/year.

\subsection{Budgetary Support}

GOI has approved a budgetary support of Rs 0.01 Billion per MW to Hydro Electricity Projects (HEPs) as informed by Ministry of Power (MOP) under Right to Information Act. GOI will have to pay and VPHEP will get Rs 4.40 Billion as budgetary support. It appears that the levelized tariff of Rs 3.92 has been calculated after taking this support into account. The levelized tariff would be higher in absence of this support. Since the levelized cost has been taken as calculated by THDCIL, the payment by GOI embedded in achieving 
this low levelized cost will be a cost to GOI or the economy. The annualized cost to GOI for providing this support @10\% will be Rs 0.44 Billion/year.

\subsection{Methodology for the Assessment of Environmental Costs}

The Central Electricity Authority (CEA) which gives the license for the generation of electricity has averred in the Techno-Economic Concurrence granted to the project that an amount of Rs 0.76 Billion has been provided in the Revised Cost Estimates towards Environment and Ecology. It is implied that all the environmental costs are compensated by this amount. In this section we shall try to arrive at the monetary values of the environmental impacts and show that the amounts allocated in Environment Management Plan (EMP) do not address these impacts at all.

We provide additional evidence from three studies of HEPs in India to assess the level and, where possible, help arrive at the monetary value of these impacts:

Study of 3 HEPs namely Maneri Bhali 1 and Maneri Bhali 2 (both in operation) and Loharinagpala (now abandoned) in Uttarakhand under a Project from Ministry of Environment, Forests and Climate Change (MOEFCC). [6] This is referred to as "Negi Study." This study gives people's perception of the impacts without making any monetary calculations.

Study of Purulia Pump Storage Project in West Bengal by Chakrabarty and others. [7] This is referred to as "Chakrabarty Study." This study has made monetary calculation of certain environmental impacts. They have been used as benchmarks with appropriate caveats due to the different nature of the VPHEP.

Study of 3 HEPs of Uttarakhand by the present author. This study undertook survey of people living near the Maneri Bhali 1 and Tehri HEPs on the Bhagirathi and the Chilla HEP on the Ganga in Uttarakhand.[8] This is referred to as "Jhunjhunwala Study." This study has given people's perception and also made monetary calculations of the value of environmental impacts for the reservoir-based Kotlibhel 1B HEP which is different from the tunnel-based VPHEP. We have used the information from this study after making changes for the different nature of VPHEP.

We now calculate the monetary value of the environmental impacts of VPHEP with this preliminary statement.

\subsection{Soil Erosion due to Modified Water Release}

\subsubsection{Brief Description of the Environmental Impact}

The Project will make a small reservoir to divert water into tunnel for transporting it to the power station. The silt will be flushed periodically. The silt will gush out in large amounts at this time. It is not clear whether the river can carry this sudden gush of silt or it will be precipitated and left somewhere below the dam. Just as butter taken out of milk, when reintroduced into the same milk does not create the same taste and texture, similarly, trapping and then flushing of sediment may not recreate the earlier balance of sediments.

\subsubsection{EIA Admits of the Environmental Impacts}

The Environment Impact Assessment (EIA) of the Project acknowledges this:

The main disadvantage is that high sediment concentrations occur during flushing events with potential negative environmental effects downstream. As an example: the model simulations have shown that flushing for 2 days with the radial gates fully open can recover 30 days of sedimentation during a "mean monsoon" period. This implies that the concentration - as an order of magnitude estimate will be 15 (=30 divided by 2 ) times larger than the natural sediment concentration in the river for the same discharge (EIA Summary Page 11).

\subsubsection{Confirmation from Other Studies}

Trapping of sediments in reservoirs makes the water 'clean' at times that the sediment is trapped. During these times the water downstream has higher capacity to absorb sediment. These sediment-free waters undertake a cutting action on the riverbed downstream. Patrick McCully, in his study of dams titled Silenced Rivers, tells us "Clear water below a dam is said to be 'hungry': it will seek to recapture its sediment load by eroding the bed and banks of the river... Over time, all the easily erodible material on the riverbed below the dam will eventually be removed, and the bed will become 'armoured' with rocks..." [9] This leads to more erosion downstream.

Proof of deprivation of sediment in both storage- and barrage type ROR dams is available from the Negi and Jhunjhunwala studies.

Table 4. Negi Study: People's Perception of Soil Erosion (Responses in Percent of Respondents).

\begin{tabular}{lllll}
\hline SI & Impacts & Increase & Decrease & Stable/Do not know \\
\hline 15 & Soil Erosion & 59.3 & 3.3 & 37.4 \\
\hline
\end{tabular}

Table 5. Jhunjhunwala Study. Question: Is there more or less sediment in the water downstream of dam? (Responses in numbers in affirmative as a ratio of total numbers of respondents).

\begin{tabular}{lll}
\hline SI No & Item & Net, HEP-wise Impact \\
\hline 1 & Chilla & Reduced $1 / 9=(-) 11 \%$ \\
2 & Maneri & Reduced $1 / 4=(-) 25 \%$ \\
3 & Tehri & Reduced $1 / 6=(-) 17 \%$ \\
4 & Average & Reduced $(-) 18 \%$ \\
\hline
\end{tabular}

Negi has averred that the impact on soil erosion does not have a relationship with the HEP. We ignore this remark because the EIA of the project points to the occurrence of such an impact and the same is confirmed by the Jhunjhunwala study.

\subsubsection{Calculation of Costs}

A study of disasters in Uttarakhand by Sajwan and others has assessed the contribution of rivers to landslides though it has not assessed the contribution of HEPs to the same.[10] We have assessed the contribution of the Project by adducing additional data and making certain assumptions. 
Table 6. Cost of Erosion

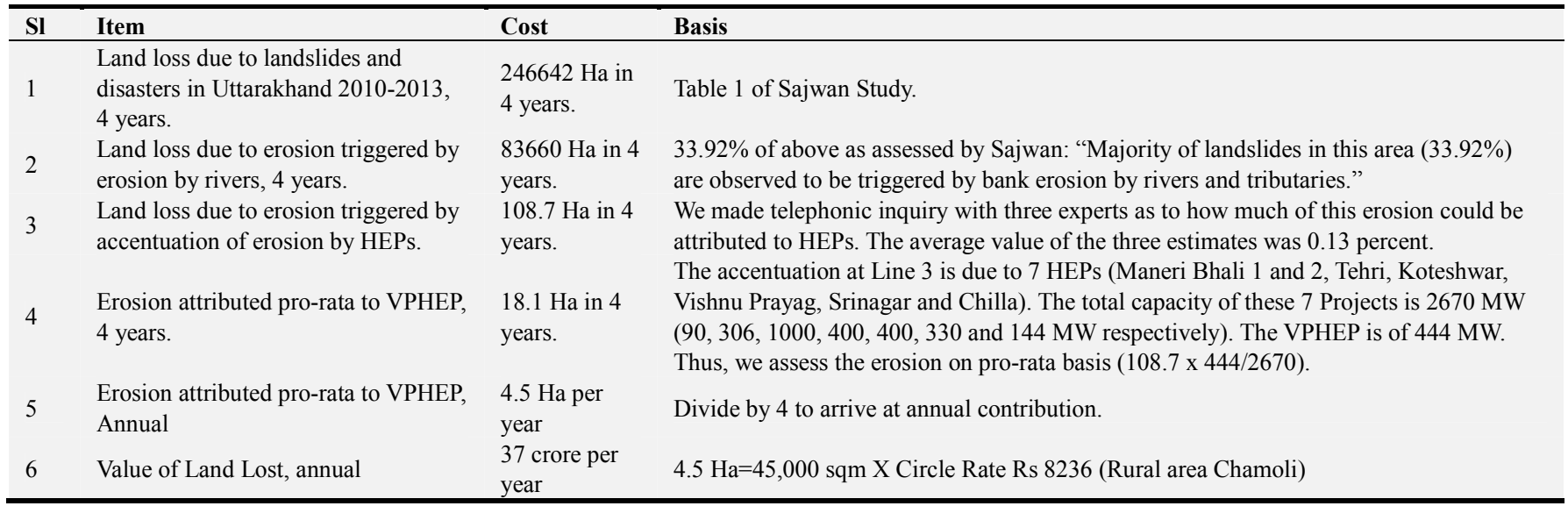

\subsubsection{EMP Provisions Are Inadequate}

The EMP provides an amount of Rs 61 lakhs for Green Belt development (Annexure 4.19.1. E). The green belt will be made in the Project Area. It may marginally reduce the erosion in the project area. It will not help prevent erosion in the entire stretch of the river as assessed by Sajwan.

\subsection{Damage to Houses Due to Blasting}

\subsubsection{Brief Description of the Environmental Impact}

The Project is tunnel based. Blasting is done in the mountains to make these tunnels. This destabilizes the hillsides leading to high incidence of landslides and greater havoc during earthquakes. Village Jamak on the rim of Maneri Bhali barrage was deeply affected during the 1992 Uttarkashi earthquake. The hillside had been destabilized during blasting and the village virtually collapsed when struck by a natural earthquake. Reportedly 85 persons died in this village.

\subsubsection{EIA Admits of Environmental Impacts}

The EIA says:

6.3 Landslide In the study area very high hazard zone (VHH) are located along the valley of riverbed, in the Patal Ganga and Birahi Ganga area where old landslide and rock debris are accumulated and along the escarpment of Karmnasa river. Moderate hazard zones are present in the north of Dungri, around Kiruli, Gadora and around Baimru area. Low hazard and very low hazardous area are mainly restricted to cultivated fields, alpine zone and in the area with gentle slope with good vegetated cover. The dam and surge shaft area come under the low hazardous zone while the TRT outfall area come under the moderate hazardous zone. Slope stabilization techniques including engineering and vegetative measures are provided in detail in EMP (EIA Summary Page 11).

\subsubsection{Additional Evidence}

Studies by Negi and Jhunjhunwala confirm the occurrence of this impact.

Table 7. Negi Study: People's Perception of Landslides (Responses in Percent of Respondents).

\begin{tabular}{llllll}
\hline SI & Impacts & Increase & Decrease & Stable & Do not know \\
\hline 15 & Landslides & 52.3 & 4.3 & 43.3 & 0 \\
\hline
\end{tabular}

Table 8. Jhunjhunwala Study. Question: Have houses developed cracks etc. after construction of dam? (Responses in numbers in affirmative as a ratio of total numbers of respondents)).

\begin{tabular}{lll}
\hline SI No & Item & Net, HEP-wise Impact \\
\hline 1 & Chilla & No impact $0 / 19=0 \%$ \\
2 & Maneri & Yes $6 / 13=(+) 46 \%$ \\
3 & Tehri & Yes $15 / 32=(+) 47 \%$ \\
4 & Average & Yes $=(+) 31 \%$ \\
\hline
\end{tabular}

We ignore the assessment by Negi that increased erosion does not have connection with HEPs because the statement in EIA points to such an impact and the same is confirmed by the Jhunjhunwala study.

\subsubsection{Calculation of Costs}

We make an assessment of this cost below.

\subsubsection{EMP Provisions are Inadequate}

The EMP says: "Plantation along the 4 approach roads and colony area will be carried to maintain slope stabilization, air quality and improvement of aesthetic view of the area." There is no plan to even stabilize the slopes of the affected villages and no recognition of the impacts of blasting which is different than slope stabilization.

\subsection{Quality of Water}

\subsubsection{Brief Description of the Environmental Impact}

Project will not store water for long periods. Yet it will negatively impact the quality of its waters for the following reasons: 
River is converted into reservoir with lower level of prana

Waters are deprived of chemicals

Waters are deprived of oxygen

Table 9. Cost of Damage to Houses During Construction.

\begin{tabular}{|c|c|c|c|}
\hline SI No & Item & Amount & Basis \\
\hline 1 & $\begin{array}{l}\text { Number of families living in the villages } \\
\text { affected by Project }\end{array}$ & 1223 Households & EIA Summary Page 25. \\
\hline 2 & Total value of houses of affected families. & Rs 2.45 Billion & Assume Rs 2 Million per house. \\
\hline 3 & $\begin{array}{l}\text { Value of houses likely to be affected due to } \\
\text { landslides }\end{array}$ & Rs 0.758 Billion & $\begin{array}{l}\text { According to survey by Jhunjhunwala Study quoted above there is a } \\
31 \text { percent chance of houses developing crack etc. due to dams. }\end{array}$ \\
\hline 4 & Cost of damage of houses & Rs 0.379 Billion & $\begin{array}{l}\text { We assume the cos of repairs and reduction in value of the house to be } \\
50 \text { percent of the value of the house. This may be an undervaluation } \\
\text { because the negative impacts of blasting on water sources and } \\
\text { landslides is not calculated separately and subsumed in this cost. }\end{array}$ \\
\hline 5 & Add costs due to trauma & Rs 0.379 Billion & Assume equal to Line 5 . \\
\hline 6 & Total One-time cost & Rs 0.758 Billion & Line $5+6$ \\
\hline 7 & Total Annualized cost & Rs 0.076 Billion Per Year & \\
\hline
\end{tabular}

\subsubsection{EIA Admits of Environmental Impacts}

The EIA admits an impact on Water Quality:

7.2 Water Quality Issue: The average discharge in the river at dam site is $182.7 \mathrm{~m} 3 / \mathrm{s} \ldots$ Low flow of the order of $35 \mathrm{~m} 3 / \mathrm{s}$ occurs in the river in the month of January, February and March... There is likely impact on the flow downstream i.e., point of diversion to tunnel to point till water is released in to the main river. This may impact on water quality, water usages downstream and so on aquatic life especially during lean periods i.e., December to February. To address the flow, aquatic and aesthetic requirement managed river flow suggests a minimum of 3 cumecs water to be made available in the stretch downstream of dam to [Tail Race Tunnel] TRT outfall where water diverted at intake will re-join the main river course. This is critical only to the stretch between the dam to $2.69 \mathrm{~km}$ downstream of the dam (that too in lean period) as beyond this point there are four to five tributaries joining the main river which contribute to the main river flow.

\subsubsection{Additional Evidence}

Waters of the Ganga River appear to have special chemical quality. In a study of Alaknanda River, Ahoy Kumar Singh and Syed I. Hasnain of School of Environmental Sciences, Jawaharlal Nehru University says: "a relatively high contribution of $(\mathrm{Ca}+\mathrm{Mg})$ to the total cations $(\mathrm{TZ}+)$ and high $(\mathrm{Ca}+\mathrm{Mg}) /(\mathrm{Na}+\mathrm{K})$ ratio indicate that the carbonate weathering could be the primary source of the major ions to these waters." [11]

A study by National Environment Engineering Research Institute (NEERI) indicates that Ganga may have small amount of beneficent radioactivity: The study titled "SelfPurification Capacity of River Bhagirathi: Impact of Tehri Dam," says: "Quantification of $\mathrm{U} 3 \mathrm{O} 8, \mathrm{ThO} 2$ and percent of $\mathrm{K}$ in sediment samples and comparison of these parameters with those present in other river sediment samples and freshwater lake sediment samples showed that Bhagirathi/Ganga sediments, collected between Grouch and Rishikesh, were more radioactive than those collected from some of the aquatic bodies in Central India."[12]

The beneficent elements are absorbed by the river water when they rub against the stones. This rubbing will be much reduced in the length of the tunnel.
Another reason for decline of quality of water is loss of cellular memory. It appears the waters of River Ganga have special spiritual powers. People from across the country come to this river to take bath and to immerse the ashes of their dead. The secret of this quality may lie in cellular memory. Lord Mahaveer says that water can feel pain and pleasure though it cannot express or act upon it. It is possible that molecules of the waters of the Ganga imbibe certain memory as they flow beside the Brahma Kapali Shila and temple of Bhagwan Badri Vishal at Badrinath, temple of Mother Ganga at Gangotri and thousands of ashrams on the banks of these rivers where monks are doing penance continually. The water is purified at a very deep level just as a smile by the mother removes millions of tensions from the mind of the child. This deep memory provides peace to the pilgrims when they take bath in these waters or carry it in bottles to their home. This cellular memory will be weakened by impounding water in reservoirs, force-flowing it through tunnels and it crashing against the turbine blades.

The negative impact is confirmed by Negi and Jhunjhunwala studies:

Table 10. Negi Study; (Responses in Percent of Respondents).

\begin{tabular}{llllll}
\hline SI & Impacts & Increase & Decrease & Stable & Do not know \\
\hline 9 & Water Pollution & 92.0 & 0 & 8.0 & 0 \\
\hline
\end{tabular}

Table 11. Jhunjhunwala Study: Was the water of river fit for drinking previously? What is the condition now? (Responses in numbers in as a ratio of total numbers of respondents)).

\begin{tabular}{lll}
\hline SI No & Item & Net, HEP-wise Impact \\
\hline 1 & Chilla & Reduced 10/20=(-) 50\% \\
2 & Maneri & Reduced 3/13=(-) $23 \%$ \\
3 & Tehri & Reduced 28/32=(-) $88 \%$ \\
4 & Average & $(-) 54 \%$ \\
\hline
\end{tabular}

Table 12. Jhunjhunwala Study: What is the change in smell of water downstream? (Responses in numbers in as a ratio of total numbers of respondents)).

\begin{tabular}{lll}
\hline SI No & Item & Net, HEP-wise Impact \\
\hline 1 & Chilla & $(-) 11 / 20=55 \%$ \\
2 & Maneri & $(-) 2 / 13=15 \%$ \\
3 & Tehri & $(-) 25 / 32=78 \%$ \\
4 & Average & $(-) 58 \%$ \\
\hline
\end{tabular}




\subsubsection{Calculation of Costs}

Murty has estimated that the economic cost of water pollution to the country is 1.73 to 2.1 percent, or median $1.9 \%$ of GDP.[13]

The District Domestic Product of District Chamoli was Rs 57.31 Billion for the year 2016-17.[14] It would be about Rs 66.34 Billion in 2019-20 (@5\% increase per year). The cost of water pollution in the district is assessed at $1.9 \%$ or Rs 1.26 Billion per year.

It could be questioned whether all of this is due to Project. Indeed the contribution to "pollution" by Project may be very little. However, there is much contribution to the loss of water quality due to the loss of beneficent chemicals and loss of cellular memory that is not tantamount to "pollution." It must be noted that Alaknanda is the main tributary of the Ganga. However, on the conservative side we take $1 / 3^{\text {rd }}$ of this value at Rs 0.42 Billion per year.

\subsubsection{EMP Provisions are Grossly Inadequate}

The EMP provides for an expenditure of Rs 0.02 Billion on muck disposal plan (Page 160 Item C). Proper disposal of muck does not reduce the impact of less absorption of beneficent chemicals or the loss of cellular memory.

\subsection{Air Pollution}

\subsubsection{Brief Description of the Environmental Impact}

The creation of air- and noise pollution during construction activities leads to health problems for the residents, livestock and vegetation.

\subsubsection{EIA Admits of Environmental Impacts}

The EIA recognizes the creation of pollution from the Project during construction:

Indirect impacts will be due to various construction activities such as generation of dust due to earthwork, excavation, transportation of construction materials (sand aggregate, cement etc.), quarry, crusher \& blasting operations, air pollution due to movement of construction vehicles, equipment and machineries, influx of labour population and pollution generated through provision of labour camps established temporarily at construction sites etc. These impacts will be limited to the construction period (EIA Summary Page 22).

\subsubsection{Additional Evidence}

Table 13. Negi Study (Responses in Percent of Respondents).

\begin{tabular}{lllll}
\hline SI & Impacts & Increase $\%$ & Decrease $\%$ & Stable/Do Not Know \% \\
\hline 1 & Air Pollution & 78 & 2 & 21 \\
2 & Noise Pollution & 69 & 3 & 28 \\
\hline
\end{tabular}

We must report that Negi does not impute these impacts to the HEPs. However, we consider these to be due to HEPs in view of the EIA of VPHEP admitting to the occurrence of these impacts.
The cost of air- and noise pollution during construction of the Purulia Pump Storage Project has been calculated by Chakrabarty at Rs 2.009 Billion. However, the Project descriptions of Purulia and VPHEP are different:

\subsubsection{Calculation of Costs}

Table 14. Parameters of VPHEP and Purulia Projects

\begin{tabular}{lllllll}
\hline SI & Project & Capacity (MW) & Reservoirs (Numbers) & Head (meters) & Tunnel (Km) & Submergence (Million M3) \\
\hline 1 & VPHEP & 444 & 1 & 237 & 16.5 (HRT + TRT) & NA (will be less) \\
2 & Purulia & 900 & 2 & 133 & 1.7 & 13.49 \\
3 & VPHEP \% Purulia & $(-) 49 \%$ & $(-) 50 \%$ & $(+) 78 \%$ & $(+) 870 \%$ & NA \\
\hline
\end{tabular}

The air and sound pollution take place during the movement of vehicles during construction. The construction activity at VPHEP is less due to less capacity and less numbers of reservoirs. On the other hand, it is more because of higher head and length of tunnel. It is not possible to assess the impact of each of these differences on air and sound pollution. Thus, we take the air and sound pollution to be proportional to the cost of the Project which is similar at Rs 24.91 Billion and 24.76 Billion for VPHEP and Purulia respectively. Chakrabarty has assessed the one-time health costs at Rs 2.009 Billion. We take this same figure for VPHEP. Accordingly, the annualized cost @ $10 \%$ is assessed at $0.2 \mathrm{Billion} /$ year.

\subsubsection{EMP Provisions are Inadequate}

The EMP provides an amount of Rs 500 thousand for
Capacity Building (Para 4.19.1. L) and Rs 2 lakhs for equipment of air monitoring (Para 4.19.1. M). Needless to say such monitoring does not eliminate the costs associated with air- and noise pollution.

\subsection{Biodiversity: Flora, Fauna and Fish Diversity}

\subsubsection{Brief Description of the Environmental Impact}

Biodiversity is an economic resource for future. The ability of living beings to adjust to changing climatic factors depends upon availability of diversity. It is possible that one variety of, say, black pepper, which provides huge economic returns today, is unable to withstand the rise in climatic temperatures. In absence of biodiversity, humankind will be deprived of pepper in future. However, other varieties of pepper may be able to withstand such increase in 
temperatures. These resistant varieties may not be profitable today. Thus, it is important to conserve such varieties as a resource for future even though they are not profitable today.

The World Commission on Dams (WCD) which was supported, among others, by Ministry of Water Resources, GOI; International Hydropower Association (representing hydropower companies); Asian Development Bank and World Bank has said that over 60 percent of the Projects studied indicated that "impeding passage of migratory fish species" was a significant impact of the dams.[15] The WCD quoted another study suggesting that the loss of free-flowing river habitat due to making of reservoirs had led to $55 \%$ of the human-induced species loss. A further 19\% was caused by dams acting as barriers to fish migration.

\subsubsection{EIA Admits of Environmental Impacts}

The EIA of Project has acknowledged the impact on biodiversity. We are giving below limited extracts to highlight the existence of the impacts and we have not given various averments underplaying the same impacts in the EIA. Our purpose here is to place a monetary value on the likely impact. For this, the existence of impact is important; not the possibility of less impact taking place.

The project... touches the boundary of the transition zone at the dam site (EIA Summary Page 14).

Three herb species Berginia ligulata (Silpara), Hedychium spicatum (Ban Haldi) and Thalictrum foliolosum (Mamiri) are reported in the forest area near Maina adit. These species fall in vulnerable category as per IUCN Red list. However these species are common in India (EIA Summary Page 16).

Himalayan Musk Deer, Goral, Leopard, Brown bear and Wild Boar are reported in Project Influence Area... The project activities are likely to disturb the normal peace of the wildlife and they are likely to move in other areas (EIA Summary Page 16-17).

Indirect impacts (on flora) will be due to various construction activities (EIA Summary Page 17).

There is likely impact on the flow downstream... This may impact on... aquatic life especially during lean periods (EIA Summary Page 19).

...two important species of Mahseer (Tor tor and Tor putitora) are present in the Alaknanda River downstream the dam site of VPHEP. These species are endangered and migratory in nature... The other species Schizothoraichthys progastus and Pseudecheneis sulcatus are vulnerable in their ecological status which has their presence in the project area (EIA Summary Page 19).

There are some specific pockets of riparian vegetation in the Alaknanda River and its tributaries especially the Birahi River, a considerable riparian vegetation cover is present which provides conducive habitat for fish... The dam construction will block the local movement of the species Schizothorax (Snow trout) (EIA Summary Page 19).

\subsubsection{Additional Evidence}

The negative impact is confirmed by the Negi Study.

Table 15. Negi Study: Impact on Biodiversity (Responses in Percent of Respondents).

\begin{tabular}{|c|c|c|c|c|c|}
\hline SI & Impacts & Increase & Decrease & Stable/Don't Know & Net \\
\hline 1 & Abundance of wildlife & 15.3 & 47.6 & 37 & (-) 32.3 \\
\hline 2 & Flora/Fauna & 4.6 & 69.6 & 25.6 & $(-) 65$ \\
\hline 3 & Habitat Fragmentation & 33.3 & 36.0 & 30.6 & (-) 2.7 \\
\hline 5 & Diversity of fish & 43.7 & 33.7 & 22.7 & (-) 10.0 \\
\hline
\end{tabular}

Negi denies relation of "abundance of wildlife" with HEPs. Our assessment, however, is that these may be due to the VPHEP as noted in the EIA.

Jhunjhunwala Study confirms the occurrence of these impacts:

Table 16. Jhunjhunwala Study: Did any trees, plants, butterfly, insects, animals, birds or fish exist previously that have now become extinct? (Responses in numbers as a ratio of total numbers of respondents).

\begin{tabular}{lll}
\hline SI No & Item & HEP-wise Impact \\
\hline 1 & Chilla & Less $4 / 19=(-) 21 \%$ \\
2 & Maneri & Less $3 / 11=(-) 38 \%$ \\
3 & Tehri & No change $0 / 26=0 \%$ \\
4 & Combined & Less $7 / 56=(-) 20 \%$ \\
\hline
\end{tabular}

Table 17. Value of Biodiversity.

\begin{tabular}{|c|c|c|c|c|}
\hline si & Study & Description & Value (Participants) & Value (India) \\
\hline 1 & $\begin{array}{l}\text { Annamalai Tiger Reserve } \\
{[16]}\end{array}$ & Eco-tourism related externalities & Rs $656 /$ year per tourist & $\begin{array}{l}\text { Rs 6.5/year India citizen (assume } 1 \\
\text { percent) }\end{array}$ \\
\hline 2 & Maldari, India [17] & $\begin{array}{l}\text { Willingness to pay for spending time for } \\
\text { participatory elephant conservation }\end{array}$ & $\begin{array}{l}\text { Rs } 6003 / \text { year per } \\
\text { agricultural household }\end{array}$ & $\begin{array}{l}\text { Rs } 60 / \text { year for India household (assume } 1 \\
\text { percent) or Rs } 12 / \text { citizen/year. }\end{array}$ \\
\hline 3 & $\begin{array}{l}\text { Khangchendonga National } \\
\text { Park, Sikkim [18] }\end{array}$ & $\begin{array}{l}\text { Improvement in environment } \\
\text { conservation }\end{array}$ & $\begin{array}{l}\text { Rs } 137 \text { per domestic } \\
\text { visitor }\end{array}$ & $\begin{array}{l}\text { Rs } 13.7 / \text { year for India citizen (assume } 1 \\
\text { percent) }\end{array}$ \\
\hline
\end{tabular}

\subsubsection{Calculation of Costs}

The valuation of the impact on biodiversity is difficult. We have been able to access following studies in South Asia regarding such valuation: 
These values of Rs 6.5, Rs 12 and Rs 13.7 per citizen are for specific ecological zones. The VPHEP is located on the Ganga River which is the National River of the country and may be considered to be equivalent to a wildlife reserve. We take the lower of these as the benchmark value. We arrive at the monetary value of biodiversity lost due to the Project as:

Number of Households, India, 2011: 0.247 Billion

Number of Households, India, 2019: 0.272 Billion

Value of Biodiversity Loss: Rs 6 per household/year

Monetary Value of Biodiversity Loss: Rs 1.632 Billion/year

\subsubsection{EMP Provisions are Inadequate}

The EMP provides for an expenditure of Rs 0.066 Billion under the head "Bio Diversity Management Plan" (Para 4.19.1. A). However, most of the expenditure is on developing an herbal garden, roadside afforestation and compensatory afforestation. These activities do not help conserve the threatened flora.

Under "wildlife protection" the only activities proposed are monitoring and awareness creation. The impacts on aquatic and terrestrial biodiversity are not mitigated by monitoring.

I recollect reading that the area is home to the endangered Cheer Pheasant. The EIA (Executive Summary) and EMP are silent on this species.

\subsection{Aesthetic Value and Reverence of the River}

\subsubsection{Brief Description of the Environmental Impact}

The flowing river has a beauty that provides happiness to the people-who live near the river, who travel to the area and those who never come to the area. The latter is known as non-use value of the flow of the river. This beauty of the flowing river is lost by making a dam. Part of the river is converted into a reservoir; and part is diverted into a tunnel with only e-flows being released.

\subsubsection{EIA Admits of Environmental Impacts}

The EIA implies that there is a loss of aesthetic value without explicitly stating the same:

To address the flow, aquatic and aesthetic requirement managed river flow suggests a minimum of 3 cumecs water to be made available... (EIA Executive Summary Page 18).

E-flows, even if enhanced to 20-30 percent as per the GOI Notification of October 2018, do not still capture the welfare obtained from uninterrupted flow and the also does not eliminate the welfare lost due to the conversion of the flowing river into a reservoir.

\subsubsection{Additional Evidence}

The Negi Study has brought out the negative impacts of the HEPs on the aesthetic and cultural values. Net 84 percent say there is decline in the aesthetic beauty of the River, net 41 percent say that there is reduction in reverence to the River and net 41 percent say there is reduction in participation in the religious festivals. Negi says these impacts are related to HEPs.

Jhunjhunwala study reports that 87 percent people liked the free-flowing river:

The abovementioned impacts have been assessed on the people residing near the rivers. These are given here only to show that such impacts do take place.

Needless to say, these impacts would also affect the people of the entire country - both who visit the area and those who do not. That is, even though one does not derive direct benefits from bathing or carrying waters, yet one likes the free-flowing river just as one likes the sun shining outside the room even though one does not bask in the sunlight.

Table 18. Jhunjhunwala Study: Do you like flowing river in contrast to a reservoir or canal?(Responses in numbers as a ratio of total numbers of respondents)).

\begin{tabular}{lll}
\hline SI No & HEP & Net Impact \\
\hline 1 & Chilla & $16 / 19=(+) 84 \%$ \\
2 & Maneri & $12 / 14=(+) 79 \%$ \\
3 & Tehri & $31 / 32=(+) 97 \%$ \\
4 & Combined & $(+) 87 \%$ \\
\hline
\end{tabular}

\subsubsection{Calculation of Costs}

Economists have developed the method of "willingness to pay' (WTP) to assess monetary value of such intangible benefits. People as asked how much they would be willing to pay for the specified result.

IIT Roorkee has estimated the non-use value of free flow of Ganga River:

The non-use value for the state of Uttarakhand by using regression output is Rs. 232554420610.35. According to 2011 census of India, population of Uttarakhand is 10086292. Therefore, WTP for a citizen of Uttarakhand comes to be Rs 23,056.

Extrapolating this data for the country level WTP is Rs 1172.00 per citizen.[19]

Conservatively, we assume this applies to a household rather than a citizen.

The total length of Ganga River is 2525 kilometres. The length of 18 tributaries of Ganga is 3638 kilometres. Total length for Ganga including the tributaries is 6163 kilometres. Of this, 16.5 kilometres or 0.27 percent will be affected by VPHEP. Accordingly, the non-use value lost by Project will be $1172 \times 0.27 \%=$ Rs 3.16 per household per year.

Another (higher) estimate is made by Jhunjhunwala:

Table 19. Question: "How much annual price you are willing to pay for restoring free flow of water in the river?" (Responses in numbers in affirmative as a ratio of total numbers of respondents)).

\begin{tabular}{lll}
\hline SI No & Name of HEP & HEP-wise Rupees per year \\
\hline 1 & Chilla, $\mathrm{n}=12$ & 71 \\
2 & Maneri, $\mathrm{n}=13$ & 136 \\
3 & Tehri, $\mathrm{n}=32$ & 20 \\
4 & Average & 76 \\
\hline
\end{tabular}

This value of Rs 76 per person/household per year is given by people living near the rivers for the particular project. The value for people of the country may be more or may be less.

We conservatively take the lower value of Rs 3.16 per household arrived at on the basis of IIT Roorkee study. Indeed the remnant loss after the release of e-flows would be 
less. However, we consider that this reduction is nullified by our using the much lower value of Rs 3.16 per household against the higher value of Rs 76 suggested by Jhunjhunwala. The total cost is calculated thus:

Number of Households, India, 2011: 0.247 Billion

Number of Households, India, 2019: 0.272 Billion

Value of Non-Use Value Lost: Rs 3.16 per household/year

Value of Non-Use Value Lost (Total): Rs 0.859 Billion/year

\subsubsection{EMP Provisions are Inadequate}

The EMP says that the release of e-flows will mitigate the loss of aesthetic value. We may record here that the e-flows have been increased from the 3 cumecs indicated in the EMP to $20-30 \%$ or about 55 cumecs now. There will be some mitigation in the sense that no stretch of the river will go dry. However, the aesthetic value will continue to be lost by the dam and due to the less-than-natural flows in the river.

\subsection{Total Environmental Costs}

Other costs that we have not calculated to keep this paper brief are as follows:

Value of forests not covered in NPV

Loss of sand and stones to local people.
Cost incurred in immersing the ashes of the dead in freeflowing water.

Loss of fishing

Drying of water springs and increase in woman's burden Cost of negative acculturation.

We have ignored these costs for the present calculation.

The total monetary value of the environmental costs calculated above are summarized below.

Table 20. Summary of Monetary Value of Environmental Costs.

\begin{tabular}{lll}
\hline Sl No & Impact & Cost Rs Billion/year \\
\hline 1 & Soil Erosion & 0.37 \\
2 & Damage to Houses due to Blasting & 0.076 \\
3 & Quality of water & 0.42 \\
4 & Air Pollution & 0.20 \\
5 & Biodiversity & 1.632 \\
6 & Aesthetic value & 0.859 \\
7 & Total & 3.557 \\
\hline
\end{tabular}

\section{Cost-Benefit Analysis}

The costs and benefits are summarized below.

Table 21. CBR of the Project.

\begin{tabular}{|c|c|c|c|c|}
\hline SI No & Item & $\begin{array}{l}\text { Costs (Rs } \\
\text { Billion/year) }\end{array}$ & $\begin{array}{l}\text { Benefits (Rs } \\
\text { Billion/year) }\end{array}$ & $\begin{array}{l}\text { Cost-Benefit } \\
\text { Ratio }\end{array}$ \\
\hline 1 & Royalty@12\% of Electricity & & 0.611 & \\
\hline 2 & Local Area Development & & 0.049 & \\
\hline 3 & Consumer cost for purchasing electricity at a higher price: 144.2 crore units @ Rs 1.97 & 2.841 & & \\
\hline 4 & Profits of THDCIL & & 1.847 & \\
\hline 5 & Employment & & 0.156 & \\
\hline 6 & Project cost annualized & 1.319 & & \\
\hline 7 & Budgetary Support annualized & 0.44 & & \\
\hline 8 & CBR Excluding Environmental Benefits and Costs & 4.60 & 2.663 & 0.58 \\
\hline 9 & Environmental Benefits: Carbon Emissions saved & & 2.324 & \\
\hline 10 & Environmental Cost & 3.557 & & \\
\hline 11 & CBR Including Environmental Benefits and Costs & 8.157 & 4.987 & 0.61 \\
\hline
\end{tabular}

The Cost-Benefit Ratio is less than 1 irrespective of whether the environmental costs are excluded or included. Yet, the project has been approved by the statutory authorities with the assumption that CBR is greater than 1 .

\section{Conclusions}

This study underscores the need for undertaking a comprehensive CBA of any project by using the best available proxy values rather than not undertaking the analysis at all.

There is a need for the Environment Management Plans to re-state the impacts as outlined in the Environment Impact Assessment and then outline how those specific impacts will be or will not be mitigated. The EMP of the Project must connect with the admitted impacts and show their adequacy or inadequacy.

There is a need to revisit the idea that hydroelectricity is "green" because it has less carbon emissions.

\section{References}

[1] Letter No 14-11/14/2019-H-I dated 20.12.2019 from Ministry of Power (MOP).

[2] Para 5.3 Page 32 Minutes of PIB dated 26.2.2007.

[3] Gill, Bigsna, et al., Electricity Pricing and the Willingness to Pay for Electricity in India: Current Understanding and the Way Forward, The Energy and Resources Institute, 2017.

[4] Moti L. Mittal, Hemendra Sharma and Richa Singh," Estimates of Emissions from Coal Fired Thermal Power Plants in India," https://www.researchgate.net/publication/267687877_Estimat es_of_Emissions_from_Coal_Fired_Thermal_Power_Plants_i n_India, Retrieved March 22, 2021.

[5] Reed Shapiro, "Value of Carbon Market Update 2020," Carbon Credit Capital, https://carboncreditcapital.com/valueof-carbon-market-update-2020/, Retrieved March 22, 2021. 
[6] Negi, GCS and Disha Punetha, People's perception on impacts of hydro-power Projects in Bhagirathi river valley, India, Environ Monit Assess (2017) 189: 138.

[7] Chakrabarty, Abhishek and Soumendu Chatterjee, Geoinformatics in Environmental Cost Assessment of Purulia Pumped Storage Project-West Bengal, Indian Journal of Geography and Environment, Volume 11, 2010.

[8] Jhunjhunwala, Bharat, Economics of Hydropower, Kalpaz, New Delhi 2009.

[9] McCully, Patrick, Silenced Rivers: The Ecology and Politics of Large Dams, Orient Longman, Hyderabad, 1998.

[10] Sajwan KS and Sushil K, "A Geological Appraisal of Slope Instability in Upper Alaknanda Valley, Uttarakhand Himalaya, India,” Journal of Geology \& Geophysics, 2016, 5: 5.

[11] Singh (1998), Abhay Kumar and Syed I. Hasnain, "Major ion chemistry and weathering control in a high-altitude basin: Alaknanda River, Garhwal Himalaya, India," Himalayan Glacier Project, School of Environmental Sciences, Jawaharlal Nehru University, New Delhi, Hydrological SciencesJournal—des Sciences Hydrologiques, 43 (6).

[12] NEERI (2004), Self-Purification Capacity of River Bhagirathi: Impact of Tehri Dam, Annual Report 2003-04.
[13] Murty, M. N. and Surender Kumar, Water Pollution in India: An Economic Appraisal, India Infrastructure Report 2011, Table 19.2, Page 289.

[14] Directorate of Economics \& Statistics, Estimates of District Domestic Product of Uttarakhand (2011-12 to 2016-17 with Base Year, 2011-12), Dehradun.

[15] World Commission on Dams, Thematic Review, Environmental Issues II. 2, Workshop on Dam Reservoirs and Greenhouse Gases, Part III, February 24 \& 25, 2000, HydroQuebec, Montreal, Final Minutes, Page 82.

[16] Surendran, A and C Sekar, An economic analysis of willingness to pay (WTP) for conserving the biodiversity, International Journal of Social Economics, July 2010.

[17] Ninan, K N, The Economics of Biodiversity Conservation: Valuation in Tropical Forest.

[18] Maharana, Iyatta, S. C. Rai \& E. Sharma, "Environmental economics of the Khangchendzonga National Park in the Sikkim Himalaya, India," Geo Journal 50, 329-337 (2000).

[19] Agarwal, Rajat, Non-use values for River Ganga, Draft Report, January 2020, IIT Roorkee. 